\title{
Contenidos y significados ideológicos en las once peliculas más taquilleras mundialmente
}

\author{
Maria Virginia Bon Pereira* \\ Asesor: Dr. José Carlos Lozano Rendón \\ Instituto Tecnológico y de Estudios Superiores de Monterrey, \\ Campus Monterrey
}

En el trabajo se analizó el contenido y el significado desde el punto de vista ideológico, de las once películas más taquilleras a nivel mundial, entre los años 2001 y 2005. La investigación se realizó en la ciudad de Monterrey, Nuevo León, durante octubre 2005 y noviembre 2006 y fue requisito final para la obtención del título de Maestra en Ciencias de la Comunicación que imparte el Instituto Tecnológico y de Estudios Superiores de Monterrey (ITESM).

El objetivo principal de la investigación fue determinar si las películas más vistas a nivel mundial transmiten concepciones e ideologías orientadas a mantener y conservar el orden hegemónico derivado de los grupos de poder. Se utilizó un análisis integral que combinó técnicas cualitativas y cuantitativas para comprender el mensaje como estructura dinámica de contenidos.

Los objetivos particulares fueron determinar qué elementos se muestran en las películas como ideológicamente dominantes y qué se muestra como alternativo (Hall, 1980); así como la identificación de las estrategias de presentación de los discursos que constituyen cada film.

Desde el punto de vista teórico se utilizó el paradigma de Estudios Culturales para estudiar los textos en términos de contenidos dominantes y alternativos (Hall, 2001). Se analizaron los elementos que conforman el contenido del mensaje, los cuales se combinan e interactúan constituyendo instancias de significado para los lectores. Se utilizó el concepto de mito (Campbell, 1959;

Uruguaya. Es Profesora de Filosofía y Licenciada en Ciencias de la Comunicación. Egresó de la Maestría en Ciencias de la Comunicación realizada en el Instituto Tecnológico de Estudios Superiores de Monterrey (ITESM) en Diciembre 2006. Ha participado en varios congresos como ponente en el área de Comunicación y Contenido Cinematográfico. 
Eliade, 1999; 1994; 2000), así como el de arquetipo (Jung, 2003), para comprender patrones de construcción de narrativas fílmicas. La hermenéutica y la semiótica fueron utilizadas para comprender los textos en relación con los diferentes discursos que se articulan en su interior, así como las posibles relaciones que se establezcan entre el texto y las formas de mirada en la investigación. La interdiscursividad y la intertextualidad se interpretaron bajo el análisis crítico del discurso (Barthes, 1967;1991; Van Dijk, 2000). El discurso fue considerado como práctica discursiva (Habermas, 2001), como lugar de interacción de fuerzas (Jensen, 1995), donde los significados van transformándose en función de las intertextualidades.

\section{Metodología}

Del universo de todas las películas producidas entre el 2001 y el 2005, según datos reportados por Imdb (2006, Febrero), se seleccionó una muestra compuesta por las 11 películas que obtuvieron mayores ingresos en taquilla a nivel mundial. Dicha muestra estuvo conformada por: El Señor de los Anillos: El Retorno del Rey, (2003); Harry Potter y la Piedra Filosofal, (2001); Shrek 2, (2004); Buscando a Nemo, (2003); La Guerra de las Galaxias. Episodio III: La venganza del Sith, (2005); El Hombre Araña, (2002); Las Crónicas de Narnia: El León, La Bruja y El Ropero, (2005); Matrix Recargado, (2003); Piratas del Caribe: La Maldición del Perla Negra, (2003); Los Increibles, (2004) y La Pasión de Cristo, (2004). En este orden de acuerdo al nivel de ingreso en la recaudación de taquilla.

De la muestra original se quitaron las secuelas de El Señor de los Anillos y de Harry Potter debido a que tenían similares patrones significativos, lo cual permitió ampliar la muestra y hacerla más diversa. Los títulos sustituidos fueron los siguientes: El Señor de los Anillos: Las Dos Torres (2002); Harry Potter y La Cámara Secreta (2002); El Señor de los Anillos: La Comunidad del Anillo (2001); Harry Potter y el Prisionero de Azkaban (2004).

El análisis se realizó de acuerdo a cuatro instancias.

En primer lugar se realizó una ficha técnica de cada film con datos filmográficos básicos y en la cual, se asignó un código a cada película.

En segundo lugar, se creó un Diario de Campo organizado de acuerdo a cuatro columnas: en la primera, Espacio y Tiempo, se realizaron anotaciones con respecto al contexto, lugar y día de la observación; en la segunda, Análisis Observacional, se anotaron las observaciones del texto (personajes, discursos, temáticas y planteos narrativos); en la tercer columna, Intertextualidad, se anotaron asociaciones con otros textos; en la cuarta columna, Interpretaciones + allá..., se 
anotaron aquellos datos relevantes como preguntas, asociaciones con conceptos del marco teórico, asociaciones con otros textos no fílmicos, etcétera.

En tercer lugar se realizó el Análisis Cualitativo de los textos fílmicos, de tipo discursivo y semiótico, encaminado a identificar los contenidos de cada film en su totalidad y en cada personaje principal y secundario. Las unidades de análisis fueron: discurso de personajes principales y secundarios; temas principales que aparecieron en la narrativa; y tópicos, es decir, lugares en los temas principales a los cuales se les dio mayor o menor importancia, así como nodos significantes alrededor de los cuales se desarrolló el conflicto y la resolución del mismo. Para cada una de las tres instancias del análisis cualitativo se diseñaron guías flexibles para identificar formaciones discursivas y las funciones que éstas cumplieron en cada film.

En cuarto y último lugar, se hizo el Análisis Cuantitativo de los textos. Se realizó un análisis de contenido sobre personajes, relaciones entre ellos y narrativas presentes en cada film. En cuanto a personajes principales y secundarios se observaron características físicas, emocionales y sociodemográficas. En cuanto a relaciones interpersonales se observaron características generales de personajes dominantes sobre otros, posibilidades de cambio y/o pluralización de dichas relaciones. En cuanto a narrativas se analizaron temas principales y el tratamiento que de ellos se hizo. Con base en el discurso de cada personaje, se identificaron lugares de confluencia de fuerzas que constituyeron y devinieron finalmente, en la narrativa del film. Las unidades de análisis cuantitativas fueron: Personajes (en lo físico, sociodemográfico y emocional); Relaciones entre personajes (dominante, no dominante y con oscilación de fuerzas); y Narrativa Fílmica (discurso de personajes y temas/tópicos). Se diseñaron hojas de codificación para personajes, relaciones y temas. Los datos se ingresaron e interpretaron con el programa de estadística spss.

\section{Conclusiones}

Las 11 películas analizadas provienen de la industria hollywoodense y priman los géneros de acción y aventura. Se trata de textos sencillos dentro de los cuales caben las caracterizaciones en cuanto a estructura que otros autores han investigado (Ang, 1998; Fiske, 1987; Hall, 2001; Jensen, 1995; McQuail, 2001). Las películas están orientadas a todo tipo de público, especialmente al adolescente y adulto.

Se trata de textos compuestos, fundamentalmente, por contenidos dominantes, que tienden a reproducir estereotipos, a transmitir la idea de orden y de 
estabilidad. Los contenidos alternativos son mínimos y están ubicados en zonas marginales de las historias, lo que facilita la pérdida de importancia dentro de la estructura global, y por tanto, que carezcan de fuerza narrativa e ideológica.

El contenido está disfrazado bajo recursos como la metáfora, la metonimia, el chiste, la ironía y la interdiscursividad, presentes en los personajes, en las relaciones que entre ellos mantienen, en los temas referenciados y en el final feliz con el que cada película termina.

La abundante implicitación de contenidos y la no discusión ni pluralización contribuyen a la normalización de contenidos que tienden a la discriminación y a la legitimación de estereotipos.

Los roles narrativos mantienen desproporción similar a la de género, presentando personajes masculinos en roles protagónicos y los femeninos en roles secundarios o terciarios.

Las historias se estructuran en forma dialéctica antagonizando bien y mal y por tanto personajes buenos y malos. En cuanto a edades, se identifica una desigualdad en tanto son representados mayormente los adultos y adultos jóvenes, quedando pobremente representados los niños y ancianos, incluso cuando se trata de películas animadas o dirigidas a público infantil.

Los personajes son representados por humanos, animales o por formas de vida inventadas (hombres virtuales, monstruos, ogros, energías incorpóreas, hadas, etc.), y aunque en algunos casos no tienen formas humanas, siempre tienen comportamientos, actitudes y acciones humanas.

Los temas más referenciados son el amor, la libertad, la vida, la felicidad y el poder. Se referencian en forma explícita, sin conflictuación ni resoluciones explícitas y en general, son los personajes protagónicos los que realizan alusiones a dichos temas. La falta de cuestionamiento interno por parte de los personajes, sugiere conductas autómatas, pasivas, guiadas por un agente externo al personaje que, en casi todos los casos, son poco reflexivas.

Cuando alguno de los personajes se muestra curioso o rebelde es el protagónico, los demás sólo acompañan apoyando o antagonizando a su misión. En estos textos se estaría sugiriendo una forma de pensar y actuar sin demasiados matices, donde las cosas son buenas o malas, positivas o negativas. Las historias contadas son protagonizadas por personajes masculinos, en un mundo ordenado y regulado por adultos, que se relacionan en base a estructuras jerárquicas de autoridad, subordinación y poder.

La falta de ubicación en un tiempo y espacios precisos produce una traslación a espacios abiertos, imaginarios, inventados que se intercalan unos a otros, 
dando la sensación de entorno mágico y fantástico, pero también deseable. Estas dimensiones y alteraciones entre espacios y tiempos, podrían hacer de los textos, productos aparentemente universales y accesibles simbólicamente a todos los públicos.

Los textos analizados tienen contenidos ideológicos que se remiten a elementos mitológicos y arquetípicos, presentes en muchas construcciones humanas (características estructurales narrativas, caracterización del héroe, temas importantes), pero las variaciones actuales tienen que ver con las formas de presentación, los modelos que se presentan como apropiados, las ausencias de diálogo y reflexión, las formas implícitas de presentar lo que se considera válido o cierto, las formas de legitimación de la violencia y el final feliz que contribuye a distender al lector, generando la costumbre en él, de participar desde fuera como espectador, sin involucrarse críticamente con el texto, obteniendo placer sin reflexión alguna.

El trabajo implicó la combinación de técnicas cualitativas y cuantitativas, lo cual enriqueció el análisis y aportó una mirada integral sobre el objeto de estudio. Desde el punto de vista teórico, se abordaron posturas y teorías como estudios culturales, lingüística cinematográfica, semiótica y hermenéutica que se combinaron, para comprender la complejidad de los textos analizados y profundizar en el análisis de personajes y discursos fílmicos. Se identificaron categorías nuevas como "mediador positivo" y "mediador negativo", que se definieron como aquellos roles de los personajes que, a favor o en contra del personaje protagónico, funcionaron como informantes de los primeros para interceder entre el lector y el protagonista/antagonista de la historia.

Como producto final de la investigación se propone la creación de productos en donde los contenidos puedan servir para que el espectador genere una conciencia reflexiva sobre el/los mundo/s que son planteados desde las películas y hacia el mundo real en que habita el espectador. Posibilitando así, que el producto no sea intrascendente y que tampoco sirva de pasatiempo evasivo de realidades, sino que contribuya a un mayor compromiso social en lo individual y en lo colectivo.

En vez de implicitar en los textos una colección de soluciones estereotipadas, modelos de felicidad, belleza, amor y vida, los creadores de los textos fílmicos podrían apostar a motivar en el espectador, formas de duda, cuestionamiento y autoplanteamientos para que cada persona genere, negociando, sus propias ideas. 


\section{REFERENCIAS}

Ang, I. (1998). Desperatly seeking the audience. Londres-Nueva York: Routledge.

Barthes, R. (1991). Análisis estructural del relato. México: Premiá.

Campbell, J. (1959). El héroe de las mil caras: Psicoanálisis del mito. México: Fondo de Cultura Económica.

Eliade, M. (1994). Lo sagrado y lo profano. Colombia: Labor.

Eliade, M. (1999). Mito y Realidad. Barcelona: Kairós.

Eliade, M. (2000). El mito del eterno retorno. España: Alianza.

Fiske, J. (1987). Televison Culture. Londres: Methuen y Co. Ltd.

Hall, S. (2001). Encoding/Decoding. En M. G. Dirham y D. M. Kellner (Eds.), Media and Cultural Studies: Keywords (pp. 166 - 176). Malden, MA, EUA: Blackwell Publishing.

Hall, S., Hobson, D., Lowe, A. \& Willis, P. (1980). Culture, Media, Language. Londres: Hutchinson.

Habermas, J. (2001). Teoría de la acción comunicativa: critica de la razón funcionalista. Vol. II: Crítica de la razón funcionalista. España: Taurus.

Imdb (2006, febrero). Obtenido el 14 de febrero de 2006 de http://www.imdb. $\mathrm{com} / \mathrm{Top} /$

Jensen, K. (1995). The social semiotics of mass communication. Thousand Oaks, California: Sage.

Jung, C. (2003). Arquetipos e inconsciente colectivo. Barcelona: Piados.

McQuail, D. (2001). Introducción a la teoría de la comunicación de masas. México: Paidós.

Van Dijk, T. (2000). Ideología. Una aproximación multidisciplinaria. Barcelona: Gedisa. 